\title{
NUTRITIONAL STATUS IDENTIFICATION AND EATING HABITS OF A REPRESENTATIVE GROUP OF PREGNANT WOMEN
}

\author{
Adriana Macri ${ }^{1}$, Fulvia Ancuța Manolache1,"* \\ ${ }^{1}$ National R\&D Institute for Food Bioresources, IBA Bucharest, 5 Ancuta Băneasa Street, Bucharest, Romania
}

Current Trends in

Natural Sciences

\begin{abstract}
There are special nutritional requirements in pregnancy, in which the intake of nutrients exerts its action both on the woman and the conception product. Therefore, the balance and diversity are the key of a proper nutrition during the pregnancy. Combining food categories is the best way to ensure nutritional balance during pregnancy period. A market research was performed on a representative sample at national level of 120 persons, in order to identify the nutritional status of pregnant women in this group. The market research highlighted the diet structure of the studied group, the categories of foods consumed weekly by the group members, as well as their frequency of consumption. The results of the study indicated a varied diet of pregnant women, but the frequency of consumption should be reviewed for certain food categories, thus: increased for: milk and dairy products, fish, oily fruits; lower, in fatty foods and salt.
\end{abstract}

Keywords: food, nutrition, nutritional status, pregnancy.

\section{INTRODUCTION}

The most recent and interesting terminology - Personalised Food - indicates a broader term, which includes more aspects related to individual personalization such as: nutritional and functional necessities, gender, age, preferences (including colour, taste, aroma, texture, shape, price), distribution, food allergies, way of life, habits, behaviour, phenotype, religion, ethics (Derossi et al., 2020).

Women in maternity leave represent an important group of population in which the diet has an important role. Pregnancy is a condition in which food personalization is essential. The impact of the adequate nutrition is two folded: both on the woman and on the product of conception. As the woman has an essential role in the perpetuation of the species, inadequate nutrition often leads quickly to disorders of the formation and development of the embryo and fetus (Koletzko et al., 2018 ).

Mother's inadequate nutrition influences her long-term health. For example, an inadequate intake of calcium and vitamin D, which would ensure both mother's and baby's needs, leads to mineral salts depletion in mother's bones, with serious consequences. Therefore, the key to proper nutrition during pregnancy is balance and variety. 
It is advisable to always respect the food balance insisting on the intake of complex proteins and carbohydrates. Associating food groups is the best way to ensure the nutritional balance during pregnancy (Koletzko et al.,2018).

EFSA proposes that energy intake be increased during pregnancy (by 70, 260 and $500 \mathrm{kcal} / \mathrm{day}$ in the first, second and third trimesters). As part of pregnancy care, women's weight gain is monitored very regularly and an energy intake that may be too low or too high can be identified.

Following a 2020 study by Zugravu et al., in Romania it is necessary to implement a standard protocol for evaluating vitamin D during pregnancy. It should include adequate nutritional advice and, in case of deficiency or insufficiency, this supplement should be prescribed. This would be a practical communication tool that could help grow the medical community and raise public awareness of the importance of vitamin $\mathrm{D}$.

The diet of pregnant women should include healthy foods, from all food groups: dairy, fruits, vegetables, grains, meat. Thus, while the need for lipids during pregnancy is slightly altered, the need for proteins $(1-1,5 \mathrm{~g} / \mathrm{kg}$ body wight/day) and carbohydrates (recommended for slow absorption) which provides the body's main source of energy increases. Most proteins (70-80\%) should be of animal origin - meat, milk, cheese, eggs and only some of the protein of vegetable origin. (Bohiltea et al.,2020). These proteins also help to absorb the vitamins A, D, E and K. A diet low in fat is a diet low in calories, but also in these vitamins. Unsaturated fats from vegetable oils, avocado, salmon, sardines are recommended. Pregnant women also need high amounts of micronutrients such as iron, calcium, folic acid and vitamin D. The pregnant woman's diet should also include dietary fiber, so important in combating constipation, which is a condition quite common during pregnancy (Lee et al. 2018).

The recommended consumption of fiber during pregnancy is 25-35 g/day. Adequate consumption of fiber and water is recommended, but without excesses, as they can cause other digestive problems such as significant loss of nutrients. A high-fiber diet helps prevent various gastrointestinal tract diseases, while ensuring optimal caloric control through long satiety. In addition to the benefits related to the digestive system (Seymour et al., 2019) fiber intake also contributes to increasing antioxidant capacity, with a vital role in fetal development.

Consumption of fruits and vegetables high in fibre helps to reduce the oxidative stress that leads to lower blood pressure, reducing the risk for preeclampsia and the percentage of miscarriages. Consumption of lignans found in nuts, seeds or vegetables is also associated with a reduced risk of cardiovascular disease or the incidence of breast cancer. It is also known that optimal consumption of fruits and vegetables during pregnancy prevents allergic diseases, spina bifida defects or anencephaly (Hajhoseini, 2013).

\section{MATERIALS AND METHODS}

The market research was performed on a representative sample at national level of 120 pregnant women, aged between 18-44 years, medium studies (31\%) and superior studies (69\%), with an average household income of 4451 lei. The market research highlighted the dietary structure of these people, the food categories weekly consumed, as well as the weekly frequency of consumption.

Computer assisted telephone interviews (CATI), using the database of people pre-recruited through face-to-face dialogue, was the data collection methodology, used to perform the market research. The selection of the respondents was made by: 


\begin{tabular}{|c|c|}
\hline \multicolumn{2}{|c|}{$\begin{array}{l}\text { Current Trends in Natural Sciences } \\
\text { Vol. 10, Issue 20, pp. 102-111, } 2021 \\
\text { ps://doi.org/10.47068/ctns.2021.v10i20.014 }\end{array}$} \\
\hline $\begin{array}{l}\text { Current Trends in Natural Sciences (on-line) } \\
\text { ISSN: 2284-953X } \\
\text { ISSN-L: 2284-9521 }\end{array}$ & $\begin{array}{r}\text { Current Trends in Natural Sciences (CD-Rom) } \\
\text { ISSN: 2284-9521 } \\
\text { ISSN-L: 2284-9521 }\end{array}$ \\
\hline
\end{tabular}

- simple probabilistic technique, by random digital dialling selection;

- non-probabilistic technique, by „snow ball” selection.

Persons' investigation was carried out on the basis of a previously elaborated questionnaire, taking into account the consumption of the main food categories (grouped into 10 categories) in the last 12 months, as well as their frequency of consumption: daily /weekly/monthly.

The questionnaire included demographic, socio-demographic and somatometric data regarding the interviewee, possible diseases, food consumption by categories and their frequency during specific intervals, frequency of adding salt to food and food supplements consumption.

Respondents are healthy women, a high percentage of them (96\%) said they do not suffer from any disease.

\section{RESULTS AND DISCUSSIONS}

The results obtained after conducting the market study on the population group "pregnant women" are presented in this paper.

From the category of meat and meat products, poultry is preferred by $98 \%$ of respondents, followed closely by fish, preferred by $90 \%$ of women and pork, preferred by $89 \%$. The lowest number of women $(17 \%)$ consume canned meat and $79 \%$ of them consume salami.

Regarding the frequency of consumption per week, poultry is consumed 3 times, fish once and pork 2 times. As shown in figure 1, sausages and salami are eaten twice a week, and lamb and seafood are eaten very rarely.

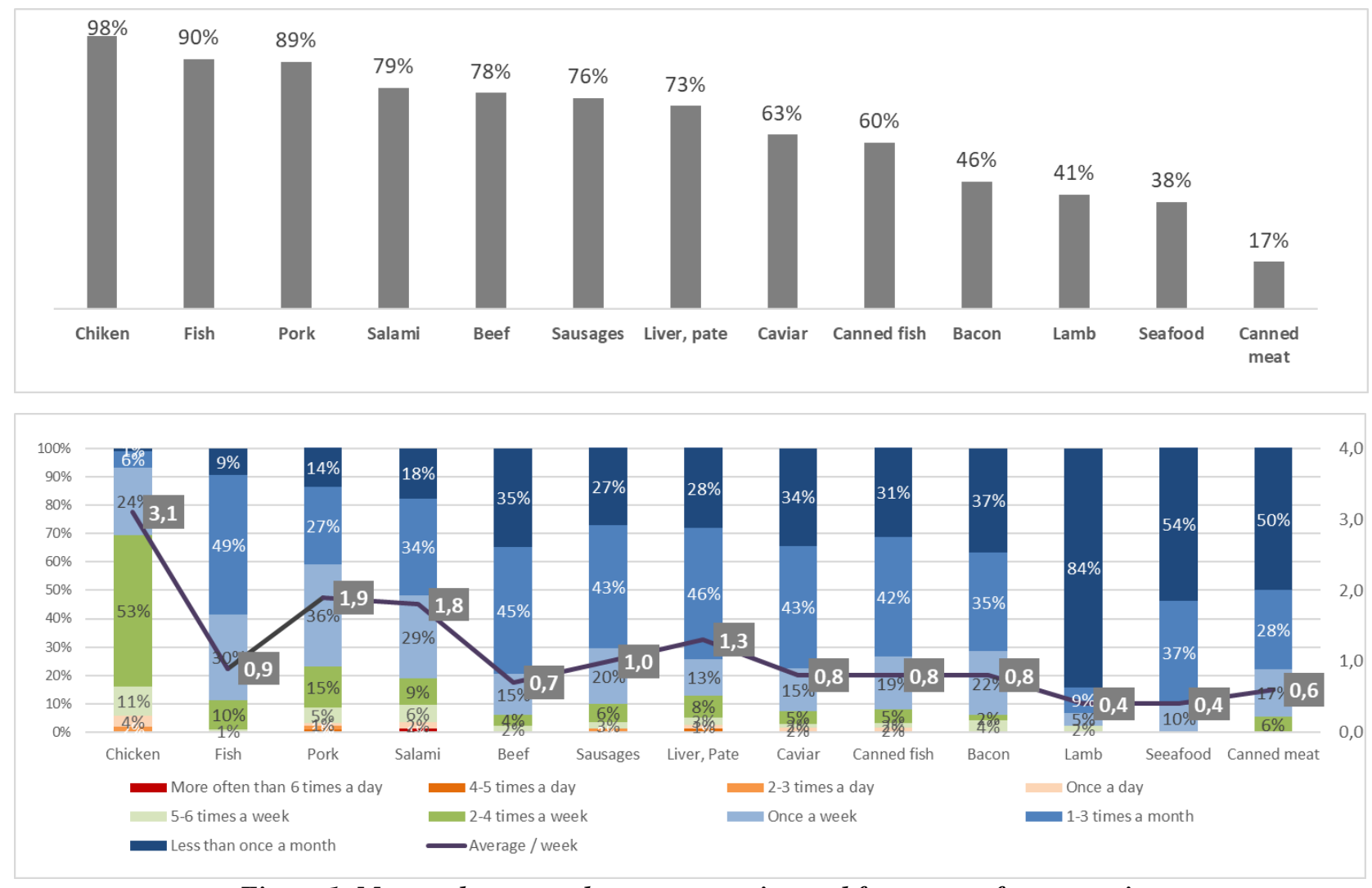

Figure 1. Meat and meat products consumption and frequency of consumption 


\section{Current Trends in Natural Sciences}

Vol. 10, Issue 20, pp. 102-111, 2021

https://doi.org/10.47068/ctns.2021.v10i20.014

Current Trends in Natural Sciences (on-line)

From the category of bakery products, a large number of respondents consume white bread, buns and croissants $(79 \%)$; the lowest percentage of pregnant women $(39 \%)$ consume bread and intermediate flour products. As it can be seen in Figure 2, 65\% of respondents consume salted biscuits. Respondents consume an average of 2 times daily white flour bakery products; brown bread and intermediate bread are consumed on an average of 5-6 days/week ( 2 times/day).

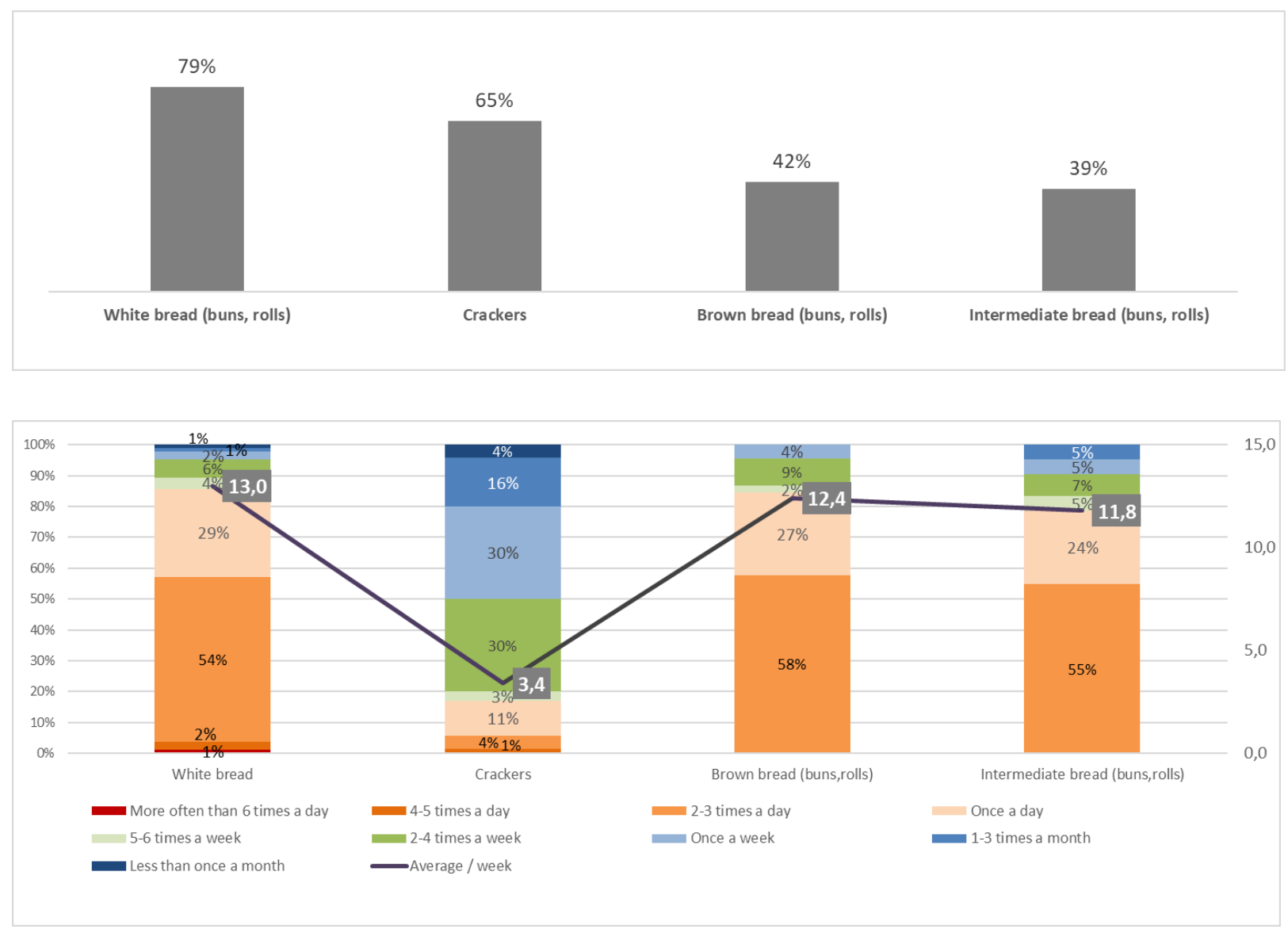

Figure 2. Bakery products consumption and frequency of consumption

As it can be seen in figure 3, half of the respondents consume cereal flakes (barley, oats, wheat, muesli) 3-4 times/week.

A category of foods rich in complex carbohydrates is often found in the diet of the pregnant women: potatoes, rice, pizza, polenta, pasta. More than $88 \%$ of them included these products in their diet. Boiled potatoes are consumed 2 times a week and rice (prepared as pilaf) 1-2 times. Pregnant women eat once/week pizza, pasta, french fries and polenta. 


\section{Current Trends in Natural Sciences}

Vol. 10, Issue 20, pp. 102-111, 2021

https://doi.org/10.47068/ctns.2021.v10i20.014

Current Trends in Natural Sciences (on-line)

ISSN: 2284-953X

Current Trends in Natural Sciences (CD-Rom)

ISSN-L: 2284-9521

ISSN: 2284-9521

ISSN-L: 2284-9521

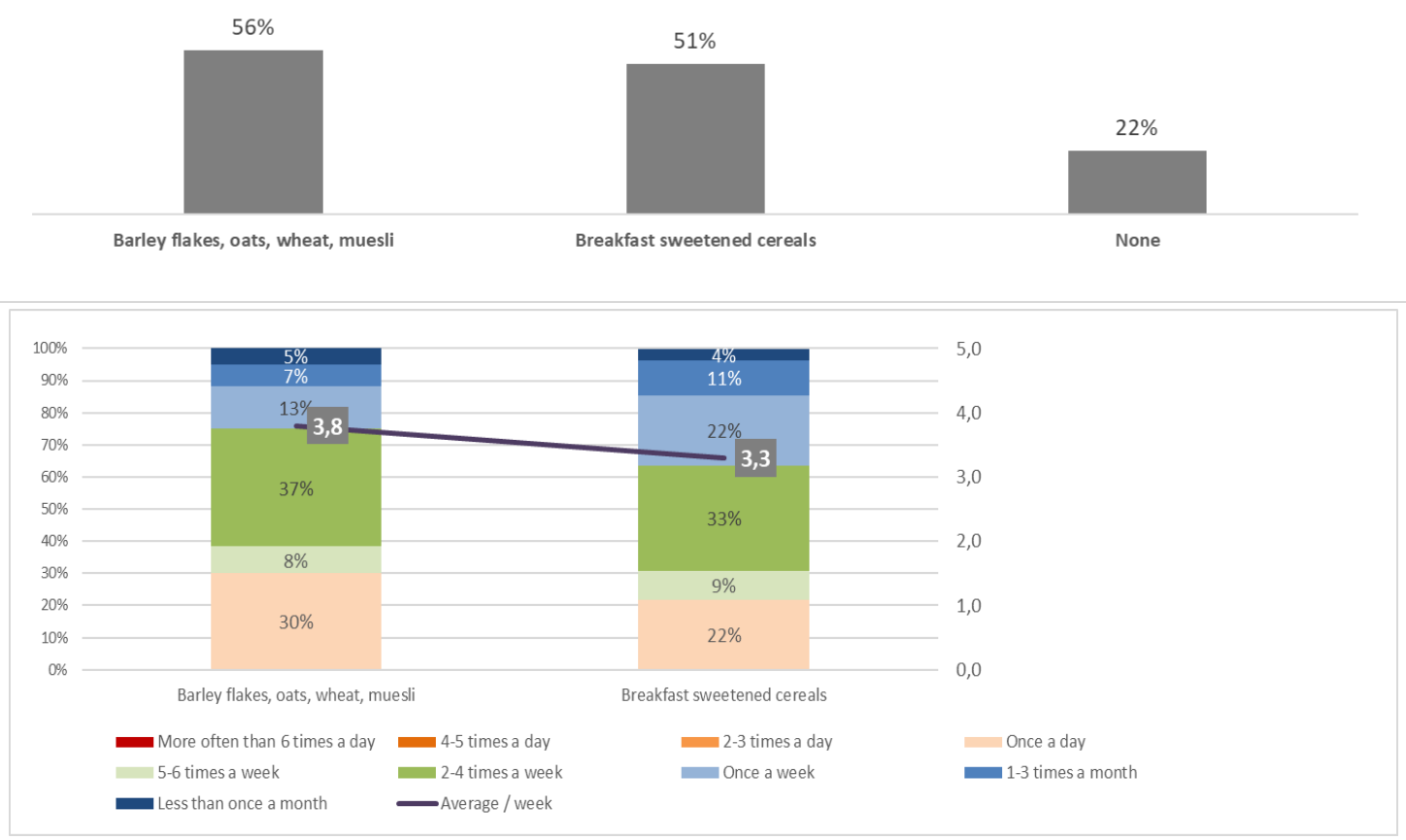

Figure 3. Frequency of consumption for cereals and flakes

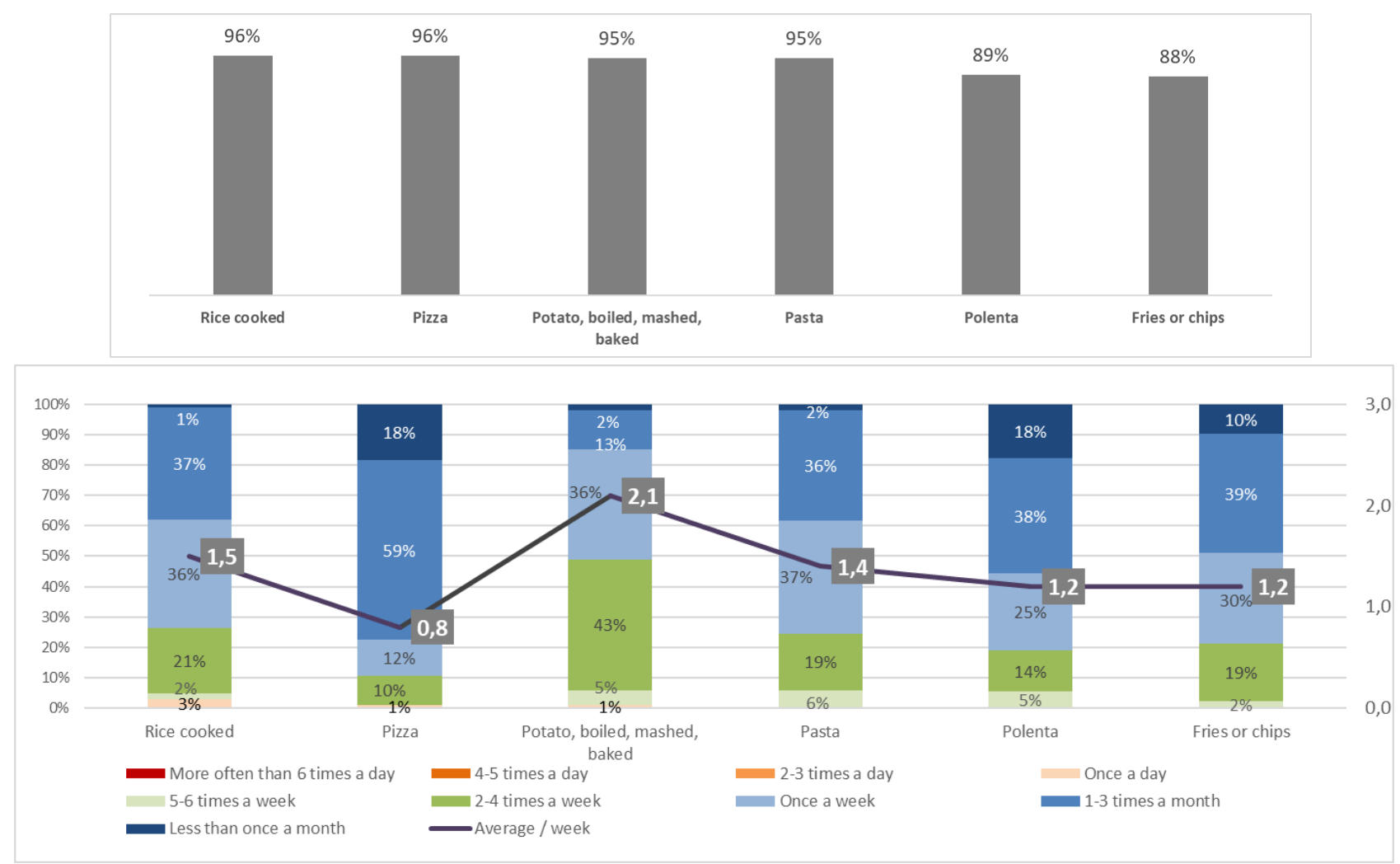

Figure 4. Consumption of carbohydrate-rich foods. Weekly consumption frequency 


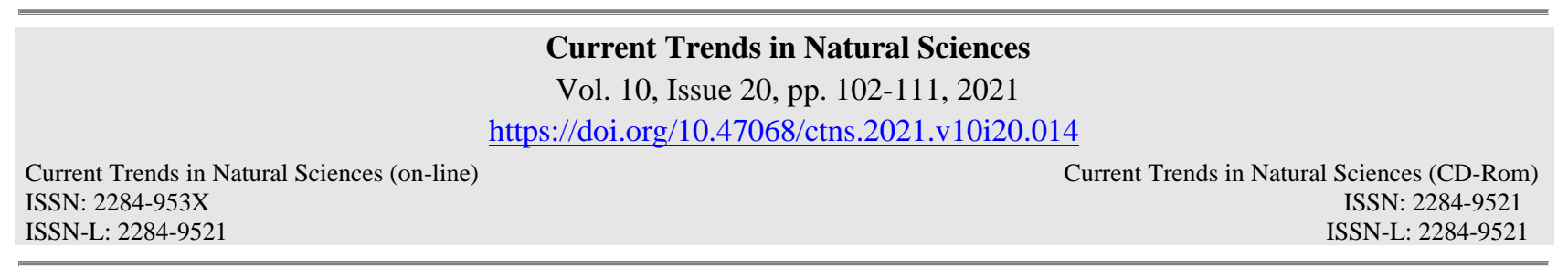

Dairy products have an important role in pregnant women's diet, given their physiological state and also given the nutritional quality of foods in this group. Therefore, $94 \%$ of pregnant women consume milk and fatty cheeses, $85 \%$ of them consume fresh cheese and $64 \%$ consume fatty yogurt. Eggs, consumed by $98 \%$ of pregnant women, were also included in this category of food.

The same graph shows the consumption of fatty foods, derivatives of eggs and dairy products, such as: mayonnaise, cream, sauces, puddings ect. Therefore, the market study showed that $93 \%$ of expectant mothers consume oil in salads, 69\% low-fat cream, and over half of them consume puddings, creams and fruit yogurt.

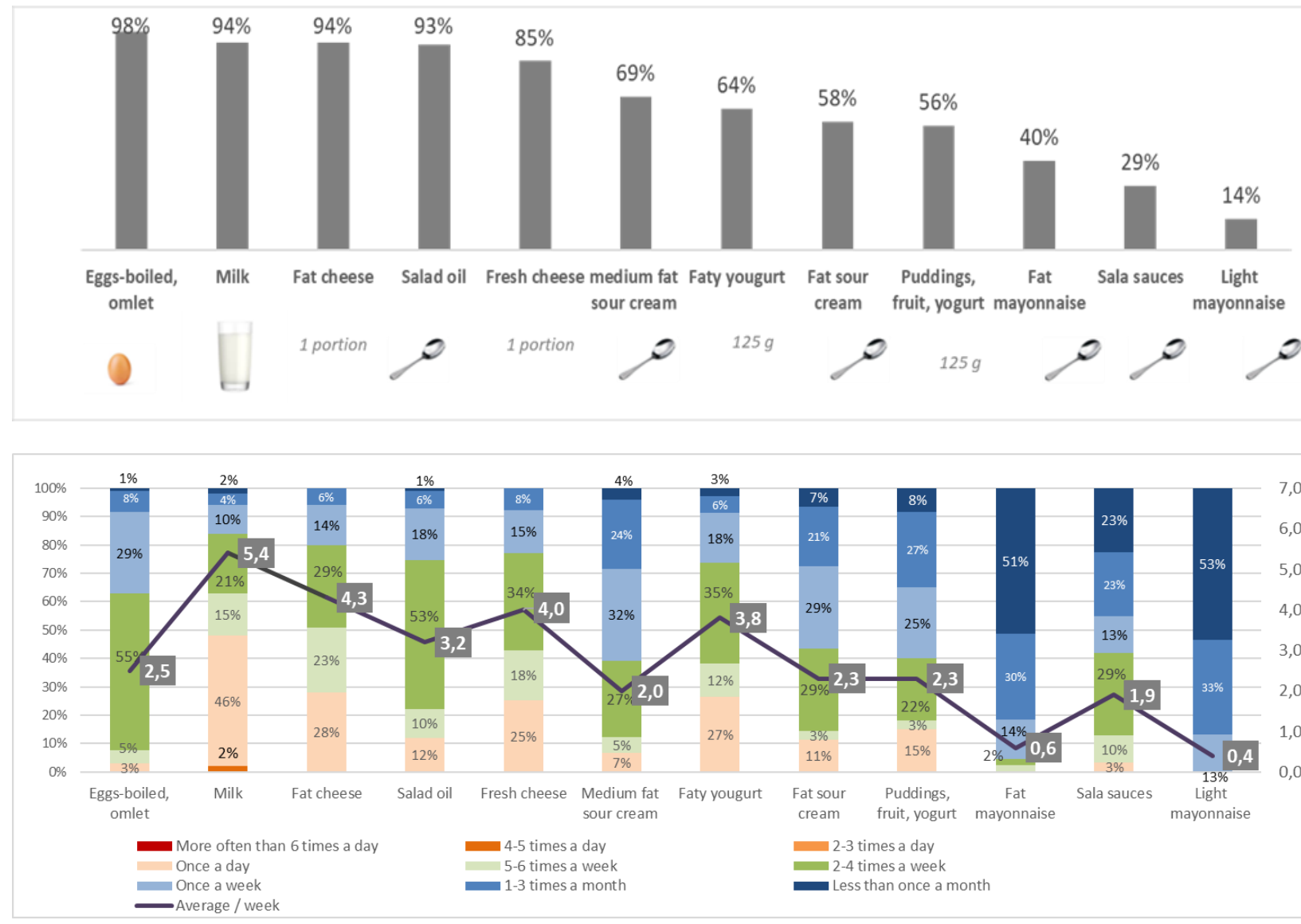

Figure 5. Diary, eggs and derivatives consumption. Weekly consumption frequency

Pregnant women consume an average of 5 glasses of milk per week and 4 times per week fatty cheeses and fresh cheese. (Figure 5) They consume an average of 2-3 eggs per week. Fatty products are consumed less frequently, except for fatty yogurt which is consumed 4 times/week.

From the category of sweets-snaks, ice cream and salty snacks are found in the diet of most pregnant women (over 93\%), being consumed 3 times/week (ice cream), respectively 2 times per week salty snacks and seeds. Chocolate and cakes are consumed by over $82 \%$ or respondents on an average of 2 times a week. $68 \%$ of pregnant women add sugar to coffee, tea and milk 5-6 times/week. 

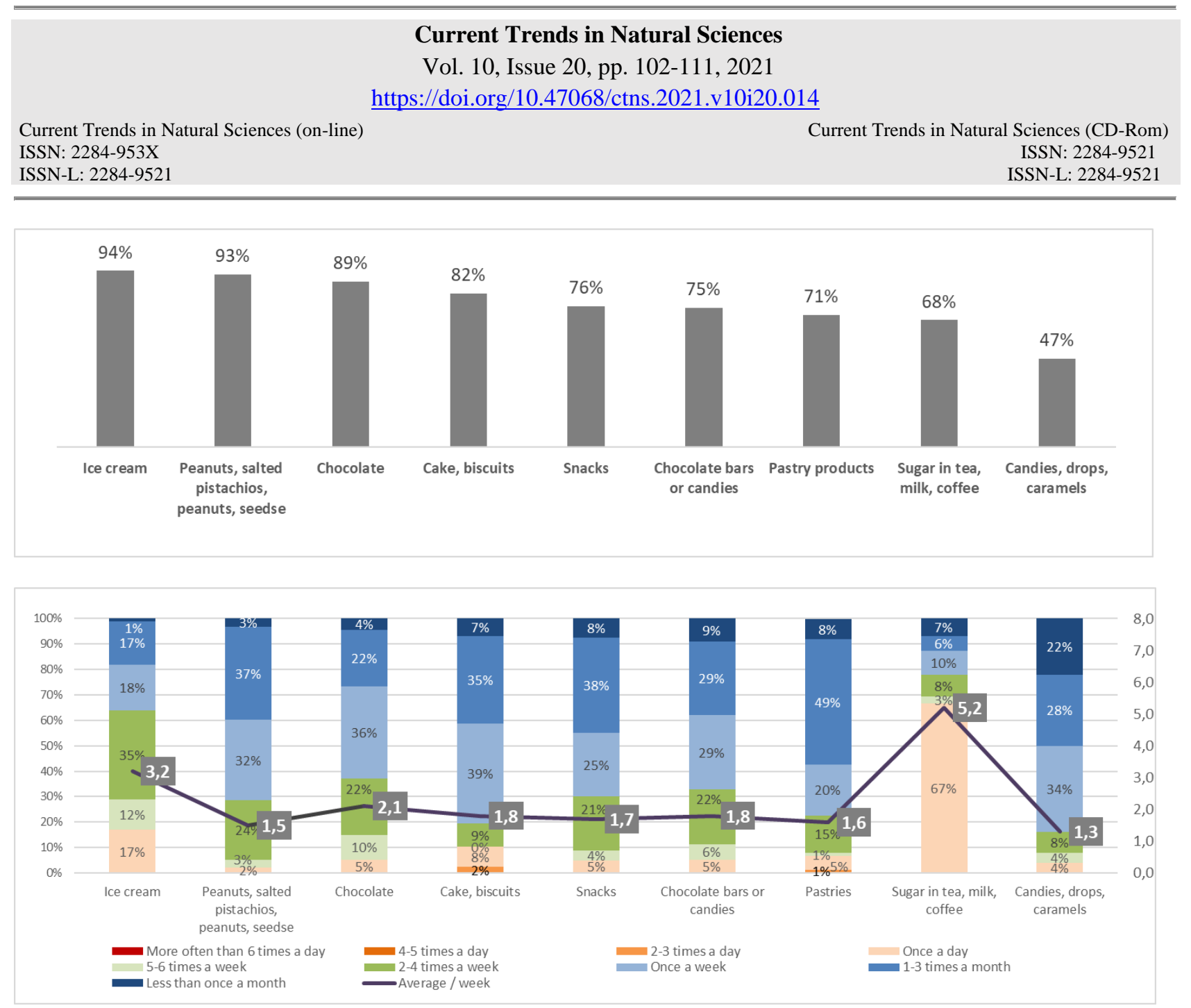

Figure 6. Sweets/snacks consumption and the frequency of consumption

Among beverages, over $82 \%$ of pregnant women consume coffee 5-6 times/week, while a small percentage of $7 \%$ prefer decaffeinated coffee. $82 \%$ of them consume tea and natural fruit juice, 3 times/week. Sweetened soft drinks are consumed by $70 \%$ of pregnant women with a frequency of 2 times/week. Alcohol is limited.

Fruits are frequently consumed and depending on the season, with a priority given to the Romanian fruits. Thus, over $95 \%$ of respondents consume: apples/pears, melons, apricots, plums, peaches, bananas and in the winter season, citrus.

As it can be seen in Figure 8, apples and pears are consumed the most, 5 times/week, apples being the fruits present on the market almost permanently. Watermelon is consumed 4-5 a week during the warm season, and bananas, which are not missing from the gallantry in all seasons, are consumed 4 times /week. Dried fruits, kiwi and other tropical fruits are consumed less often, 1-2 times/week. 


\section{Current Trends in Natural Sciences}

Vol. 10, Issue 20, pp. 102-111, 2021

https://doi.org/10.47068/ctns.2021.v10i20.014

Current Trends in Natural Sciences (on-line)

ISSN: 2284-953X

Current Trends in Natural Sciences (CD-Rom)

ISSN: 2284-9521

ISSN-L: 2284-9521

ISSN-L: 2284-9521
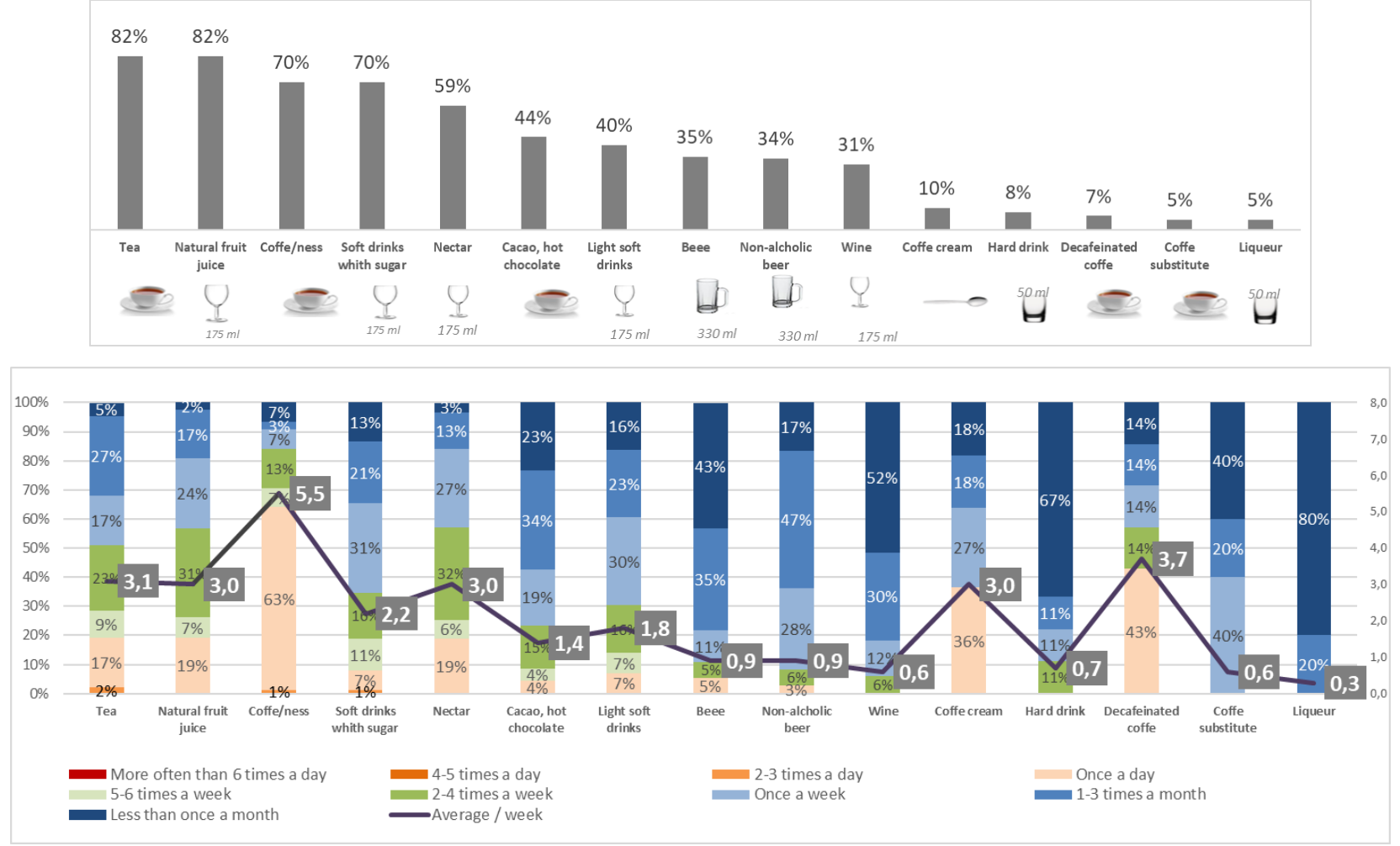

Figure 7. Consumption and frequency of consumption for beverages
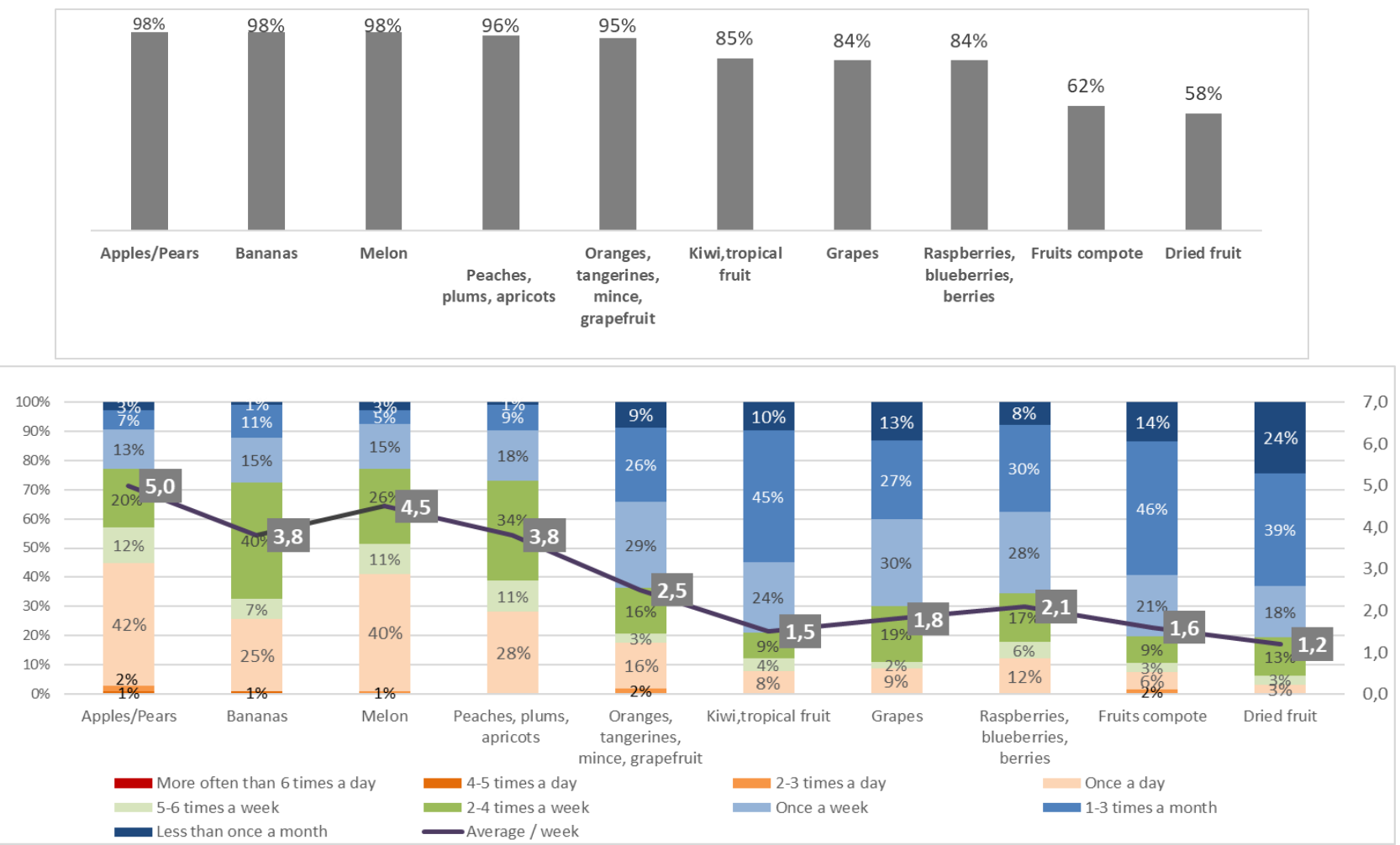

Figure 8. Consumption and frequency of consumption for fruits 


\begin{tabular}{lc}
\hline & $\begin{array}{c}\text { Current Trends in Natural Sciences } \\
\text { Vol. 10, Issue 20, pp. 102-111, 2021 } \\
\text { https://doi.org/10.47068/ctns.2021.v10i20.014 }\end{array}$ \\
\cline { 2 - 2 } $\begin{array}{l}\text { Current Trends in Natural Sciences (on-line) } \\
\text { ISSN: 2284-953X }\end{array}$ & Current Trends in Natural Sciences (CD-Rom) \\
ISSN-L: 2284-9521 & ISSN: 2284-9521 \\
ISSN-L: 2284-9521 \\
\hline
\end{tabular}

A diverse range of vegetables is consumed by pregnant women, so that out of 20 groups of vegetables included in the questionnaire, 10 were voted by more than $90 \%$ of respondents, as they regularly consume these groups of vegetables. Peppers, tomatoes and roots are consumed by almost all women $(98 \%)$.

As it can be observed in Figure 9, tomatoes are eaten on an average of 6 times/week, carrots/celery 5 times/week and onions 4 times. Peppers/donuts are eaten 3-4 times a week and garlic 3 times. Soy products are not very popular, their frequency of consumption is low.
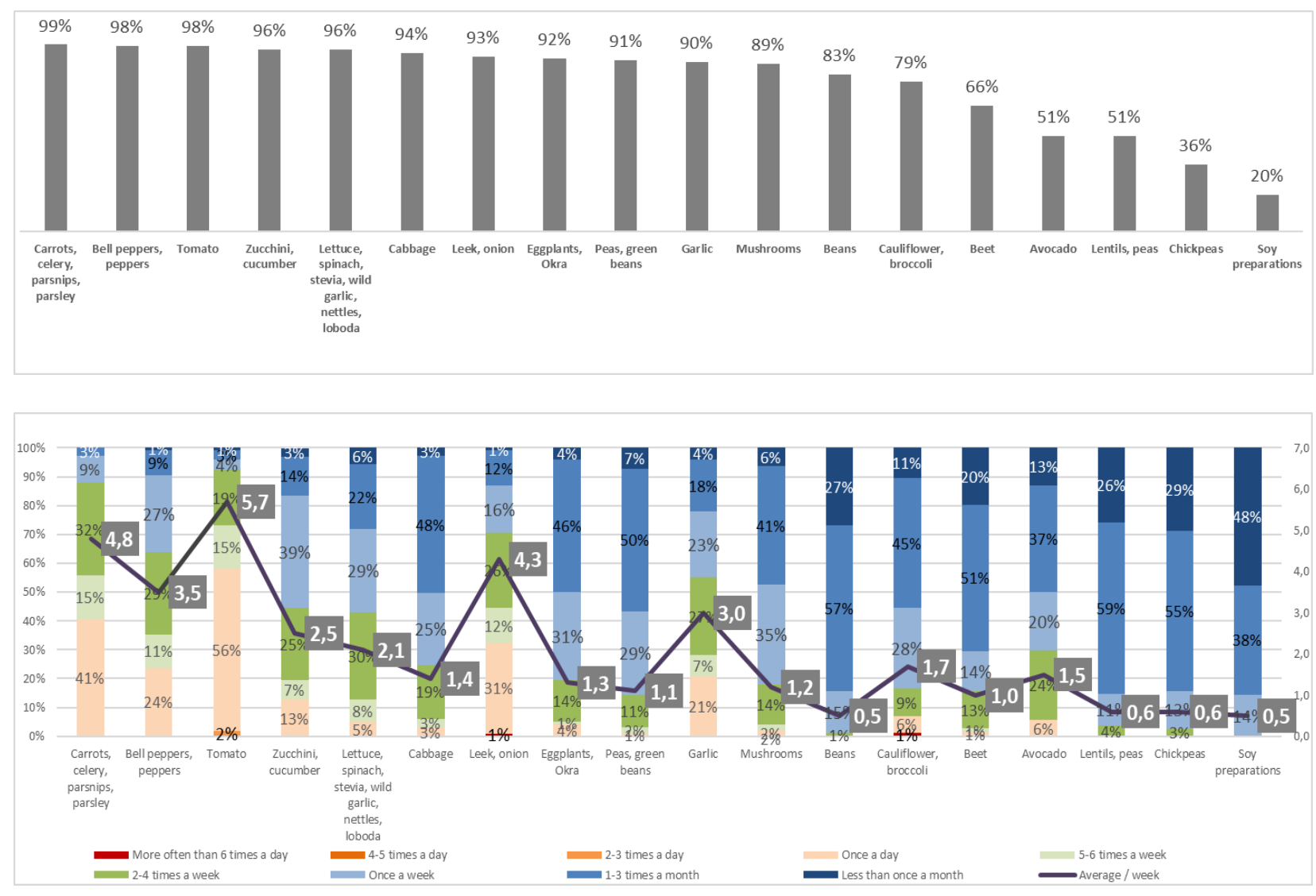

Figure 9. Consumption and frequency of consumption for vegetables

Pregnant women who were part of the study add salt in their food in a percentage much too high for their condition: $49 \%$ add salt always, $28 \%$ add salt usually.

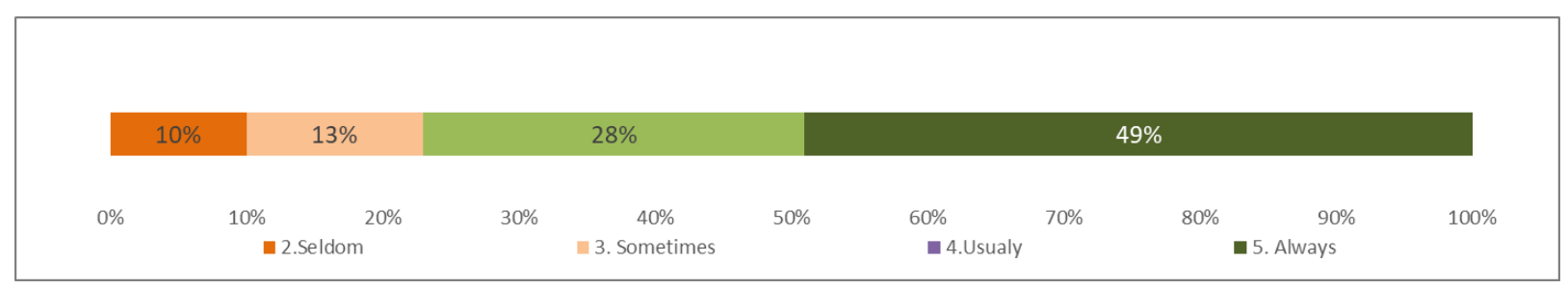

Fig 10. Frequency of adding salt to food 


\section{Current Trends in Natural Sciences}

Vol. 10, Issue 20, pp. 102-111, 2021

https://doi.org/10.47068/ctns.2021.v10i20.014

Current Trends in Natural Sciences (on-line)

\section{CONCLUSIONS}

Generally, the results of the study indicated a varied diet of pregnant women, but the frequency of consumption should be reviewed for certain food categories, thus:

- daily consumption of dairy products should be increased (milk, yoghurt, cheese); 4 servings per day are recommended;

- the fish consumption should be also increased from once to twice per week, from which one time should be oily fish (e.g., salmon, herring, trout etc);

- animal fats consumption (butter, cream) should be limited;

- the pregnant women prefer the white bakery products (bread, rolls, buns); for a healthy diet they have to opt for wholegrain cereal foods or brown bread;

- fruits and vegetable consumption is optimal;

- the daily salt intake in the pregnant women diet is too high; this consumption should be limited to the optimal quantity (5 g/day).

\section{ACKNOWLEDGEMENTS}

This study was achieved through Core Program, with the support of the Ministry of Research, Innovation and Digitalization, contract 22N/2019 (project PN 190201 02).

\section{REFERENCES}

Bohiltea, R.E., C.A., Nemescu, D., Turcan N., Paulet, F.P., Gherghiceanu, F., Ducu, I., Cirstoiu, M.M. (2020). Impact of obesity on the prognosis of hypertensive disorders in pregnancy, Exp Ther Med., 20(3), 2423-2428.

Derossi, A., Husain, A., Caporizzi, R., Severini, C. (2020). Manufacturing personalized food for people uniqueness. An overview from traditional to emerging technologies. Critical Reviews In Food Science And Nutrition, 60(7), 1141-1159.

Hajhoseini, L. (2013). Importance of optimal fiber consumption during pregnancy, Int J Women's Health Reproduction Sci, 1(3), 76-79.

Koletzko, B., Cremer, M, Flothkötter, M., Graf, C., Hellmers, H.C., Kersting, M., Krawinkel, M., Przyrembel, H., RöblMathieu, M., Schiffner, U., Vetter, K., Weißenborn, A.,Wöckel, A. (2018). Diet and Lifestyle Before and During Pregnancy - Practical Recommendations of the Germany-wide Healthy Start - Young Family Network. Geburtshilfe Frauenheilkd, 78(12), 1262-1282.

Lee, Y.Q., Collins, C.E, Gordon A., Rae, K. M., Kirsty, G P. (2018). The Relationship between Maternal Nutrition during Pregnancy and Offspring Kidney Structure and Function in Humans: A Systematic Review, Nutrients, $10(2), 1-24$.

Seymour, J. D., Beck, K, Conlon, C. (2019). Nutrition in pregnancy, Review, Obstetrics, Gynaecology and Reproductive medicine, 29, 219-224.

Zugravu, C, Rascu, A, Otelea, M, Macri, A. (2020). Vitamin D intake from food and supplements in pregnancy, a pilot study, Rev Farmacia, 68(1), 150-154. 